\title{
Editorial
}

\section{O cuidado de enfermagem como presença significativa: uma interseção entre a criatividade e a tecnologia}

Nos últimos anos, vimos insistindo na presença do enfermeiro junto aos pacientes, especialmente no âmbito hospitalar, como uma forma autêntica de produção de sentido em meio ao processo de hospitalização, de dor, de sofrimento, de perdas e de morte ${ }^{1}$. Este profissional, a partir de seus conhecimentos científicos, de sua capacidade técnica, de sua experiência na administração de unidades de saúde, de sua permanência constante ao lado das pessoas que enfrentam o processo de adoecimento, de sua capacidade de observação e das possibilidades de relação humana estabelecidas no cotidiano do trabalho, apresenta-se como um elemento central no processo de trabalho nas instituições hospitalares e de cuidado/conforto na estabilização das agressões orgânicas, na recuperação da saúde e/ou no processo de morrer enfrentado por aqueles que estão sob seus cuidados.

Desse modo, o cuidado de enfermagem se constitui como uma presença significativa que extrapola os limites do físico e se constitui, também, na pré-ocupação com o paciente e seu contexto. Concordamos que este cuidado inclui a presença como forma de se estimular o outro a ser mais a partir da ideia de proximidade ética ${ }^{2}$. O cuidado de enfermagem a partir da presença autêntica e da proximidade ética implica na ajuda para que o outro seja, na promoção do seu ser, na demonstração de um investimento que requer o próprio cuidador e ser cuidado em uma proximidade que estimule o exercício da essência humana de ambos e na exigência da atitude de velar pela integridade e pela unidade do ser dos dois atores sociais².

Nessa esteira, o cuidado de enfermagem implica a colaboração para que o outro possa ser, mas a sê-lo em sua singularidade e em sua especificidade, com minimização das imposições que normalmente caracterizam as interações exercidas no ambiente da saúde. Cria-se aqui um espaço de relações que se torna fértil para o desenvolvimento humano e para a concretização do novo e do ainda não experimentado, o inusitado que tende a ser sufocado pelo seguimento inflexível das normas, rotinas e protocolos.

Uma das dimensões deste espaço de relações se corporifica na criatividade desenvolvida pelos enfermeiros e suas equipes nas diferentes unidades de saúde, que engloba tanto o técnico e o tecnológico, quanto o psicológico e o afetivo. A realização de grupos de discussão em diferentes cenários, um momento específico para a realização de atividades laborais que estimulem a negociação de conhecimento, a verbalização das dificuldades encontradas e a possibilidade de soluções conjuntas, a abertura das unidades de saúde às ações de diferentes grupos e organizações não governamentais, a proposição de técnicas e tecnologias para cuidados e situações específicos e a utilização dos talentos dos profissionais podem ser exemplos de uma das dimensões do que chamamos de espaço de relações.

Nos próximos dois parágrafos, citaremos estudos que mostrem duas dimensões fundamentais deste espaço de relações, quais sejam um mais artístico e lúdico e outro mais técnico/tecnológico. No que tange ao artístico/lúdico, baseamo-nos na dissertação de Bergold $^{3}$ que procurou analisar a atividade de visitas musicais desenvolvidas pela enfermeira de uma determinada instituição militar aos pacientes e seus familiares, assim como a repercussão dessas visitas na saúde e no conforto dos que a recebiam. Os pacientes se referiram à influência positiva destas visitas na promoção do conforto e do bem-estar, ao mesmo tempo em que permitiam a expressão de emoções que, de um modo geral, tendem a permanecer na invisibilidade no contexto das unidades de saúde. Este conjunto elencado pelos pacientes termina por promover, segundo eles próprios, sua integridade e o resgate de sua autonomia, a partir do respeito ao seu estilo musical e ao estímulo à criação de recursos próprios. Apontaram, ainda, a qualidade integradora das visitas musicais em função do estímulo à comunicação e à interação entre os seus participantes e entre estes e a equipe de enfermagem.

Na dimensão técnica/tecnológica, Souza et al. ${ }^{4}$ ressaltam a existência de um dispositivo adaptado para verificação de diurese horária sem conexão com um cateter vesical, mas sim ligado a um dispositivo de incontinência urinária. Trata-se da utilização de um frasco de dreno com capacidade de armazenamento de $1000 \mathrm{ml}$, com uma fita adesiva lateral graduada, ligado a uma bolsa coletora de urina com sistema fechado. Desse modo, segundo os próprios autores, evita-se o risco de infecção e possibilita-se uma mensuração mais fidedigna em 
função das características das citadas bolsas coletoras. Destacamos, ainda, que já observamos, em vários momentos, a proposição, por parte dos profissionais da enfermagem, de dispositivos tecnológicos construídos no interior do cotidiano e das necessidades dos pacientes que obedecem às recomendações técnicas e que, simultaneamente, promovem bem-estar, conforto e alívio. Estas proposições nascem do encontro entre a criatividade dos profissionais, sua sensibilidade para as necessidades objetivas e subjetivas dos sujeitos cuidados, a clareza das deficiências institucionais e/ou tecnológicas, a empatia pela condição do outro e o desejo de contribuir para a resolução, ou pelo menos amenizar situações desagradáveis ou desconfortantes.

Pontuamos, encerrando este editorial, que as dimensões artísticas e técnicas, afetivas e tecnológicas da enfermagem possuem, no cuidado, um lugar de encontro e de convívio; assim cada profissional tem a possibilidade de se constituir como uma presença significativa, a partir do seu estar próximo fisicamente, da criatividade no exercício de suas aptidões e habilidades e da implementação do conhecimento técnico-científico na inovação do fazer de antigos procedimentos e na proposição de novas tecnologias na combinação de diferentes instrumentais.

Antonio Marcos Tosoli Gomes

Editor Associado

\section{Referências:}

1.Gomes AMT. A vulnerabilidade como elemento organizador do cuidado de enfermagem no contexto do HIV/aids: conceitos, processos e representações sociais [tese]. Rio de Janeiro: Universidade do Estado do Rio de Janeiro; 2011. 2.Torralba I, Roselló F. Antropologia do cuidar. Petrópolis (RJ): Vozes; 2009.

3.Bergold LB. A visita musical como estratégia terapêutica no contexto hospitalar e seus nexos com a enfermagem fundamental [dissertação de mestrado]. Rio de Janeiro: Universidade Federal do Rio de Janeiro; 2005.

4.Souza NVDO, Santos DM, Anunciação CT, Thiengo PCS. O trabalho da enfermagem e a criatividade: adaptações e improvisações hospitalares. Rev enferm UERJ. 2009; 17:356-61. 